\title{
PERFIL E EXPECTATIVAS DOS ALUNOS CONCLUINTES DOS CURSOS TECNICOS INTEGRADOS DO IFRN, CAMPUS APODI
}

\author{
S. R. G. OLIVEIRA, F. R. C. MOREIRA* E F. F. M. SILVA \\ Instituto Federal do Rio Grande do Norte \\ faviano.moreira@ifrn.edu.br
}

Artigo submetido em março/2014 e aceito em novembro/2014

DOI: $10.15628 /$ holos.2014.2046

\section{RESUMO}

Este trabalho teve por finalidade caracterizar o perfil e as expectativas dos alunos dos terceiros e quartos anos dos cursos técnicos integrado de Zootecnia e Biocombustíveis do Instituto Federal de Educação, Ciência e Tecnologia do Rio Grande do Norte - Campus Apodi. A pesquisa foi realizada com 138 alunos, através da aplicação de questionários com perguntas abertas e fechadas. A análise dos dados foi realizada de maneira descritiva e os mesmos apresentados em percentuais. Os principais resultados mostraram que as mulheres são maioria $(60,9 \%)$ e que a idade média foi de 17,4 anos. $99,3 \%$ dos alunos afirmaram querer cursar uma faculdade e a Universidade Federal do Rio Grande do Norte foi a instituição mais citada. Os cursos mais citados pelos discentes foram: Medicina, Ciência e tecnologia, Engenharia química, Engenharia civil, Direito e Medicina veterinária. Quanto a prática profissional, $89,9 \%$ dos alunos a realizam na forma de projetos de pesquisa ou extensão e $10,1 \%$ na forma de estágios. Mais de $97 \%$ dos estudantes estão satisfeitos com as disciplinas, porém $64,5 \%$ não estão satisfeitos com a quantidade de aulas práticas dos cursos. Quanto ao mercado de trabalho, $58,8 \%$ acreditam que há boas oportunidades. Dessa forma, conclui-se que são necessárias medidas para qualificar o ensino dos alunos, todavia, as mesmas dependem de uma gestão democrática que analise a opinião de toda a comunidade escolar.

\section{PROFILE AND EXPECTATION OF THE STUDENTS CONCLUDING OF THE COURSE TECHNICIAN OF IFRN, CAMPUS APODI}

\begin{abstract}
This study aims to characterize the profile and expectations of students in third and fourth years of integrated technical courses in Animal Science and biofuels, from Federal Institute of Education, Science and Technology of Rio Grande do Norte - Campus Apodi. The survey was conducted with 138 students, through the use of questionnaires with open and closed questions. Data analysis was performed descriptively and presented in percentage. The main results showed that women are the majority (60.9\%) and the average age was 17.4 years. 99.3\% of students said they want to attend college and the Federal University of Rio Grande do Norte was mentioned institution. The courses most frequently cited
\end{abstract}

by students were: Medicine, Science and Technology, Chemical Engineering, Civil Engineering, Law and Veterinary Medicine. As a professional practice, $89.9 \%$ of students performing in the form of research projects or extension and $10.1 \%$ in the form of internships. Over $97 \%$ of students are satisfied with the disciplines, but $64.5 \%$ are not satisfied with the amount of practical classes of the courses. As for the labor market, 58.8\% believe that there are good opportunities. Thus, are necessary measures to qualify the student teaching, however, depend on the same of a democratic management to consider the opinion of the whole school community.

KEYWORDS: education, questionnaire, quality, Rio Grande do Norte. 


\section{INTRODUÇÃO}

A lei que institui a criação dos Institutos Federais de Educação, Ciência e Tecnologia (Lei 11.892 de 29/12/2008) no Brasil em seu Artigo $2^{\circ}$ estabelece que as mesmas são instituições de educação superior, básica e profissional, pluricurriculares e multicampi, especializados na oferta de educação profissional e tecnológica nas diferentes modalidades de ensino.

O Instituto Federal de Educação, Ciência e Tecnologia situado na cidade de Apodi, Rio Grande do Norte (IFRN), é uma instituição que oferta educação profissional nos níveis técnico e tecnológico, através dos cursos técnicos em Zootecnia, Biocombustíveis, Agricultura e Informática, além do Curso Superior de licenciatura em Química. A entrada de novos alunos acontece por meio de testes de seleção e são aprovados aqueles que obtém êxito nas notas que são necessárias para o ingresso na escola. As primeiras turmas de integrado da instituição na cidade de Apodi se formarão até o ano de dois mil e quinze, com os cursos de técnico em Biocombustíveis e Zootecnia.

Neste sentido conhecer as expectativas e anseios dos alunos de uma Instituição de ensino mostra-se bastante pertinente dentro de um contexto pedagógico, o que possibilita uma análise da atual política de educação do Instituto e permite adequações das práticas pedagógicas e administrativas, assim como a superação de eventuais falhas e possíveis ajustes na condução do processo de ensino aprendizagem.

Dessa forma, o presente trabalho teve por objetivo caracterizar o perfil e expectativas dos alunos de terceiros e quartos anos dos cursos técnicos em Biocombustíveis e Zootecnia, na modalidade integrado.

\section{MATERIAS E MÉTODOS}

A pesquisa foi realizada através da aplicação de questionários com os alunos dos terceiros e quartos anos dos cursos de Técnico em Zootecnia e Biocombustíveis, na modalidade integrado, durante o mês de junho/2013, quando os alunos cursavam o primeiro semestre do respectivo ano letivo. Foram aplicados 138 questionários em espaço cedido pelos professores durante o desenvolvimento das aulas.

A pesquisa enfocou a caracterização dos alunos (idade, sexo e curso) e expectativas sobre o curso com as seguintes perguntas:

- Você tentará algum curso superior? Se sim, qual e onde? Se não, por que?

- Caso você passe para um curso superior antes da conclusão do curso técnico, você desistiria do curso? Por que?

- Você já fez ou está fazendo a prática profissional? Se sim, é na forma de projeto de pesquisa/extensão ou estágio? Se não, por que?

- Você está satisfeito com a qualidade do ensino das disciplinas básicas?

- Você está satisfeito com a qualidade do ensino das disciplinas técnicas?

- Você está satisfeito com a quantidade de aulas práticas do seu curso? Por que?

- Você acredita que seu curso oferece um bom mercado de trabalho?

- Você acredita que a quantidade de turmas formadas pelo IFRN é suficiente para atender a região? 
- Qual a sua sugestão para melhorar o curso?

Foi realizada uma análise descritiva sobre os dados encontrados.

\section{RESULTADOS E DISCUSSÕES}

Na Tabela 1, pode ser observado a caracterização dos alunos do IFRN quanto ao sexo e idade, onde as mulheres são maioria com exceção dos discentes do $3^{\circ}$ ano do curso técnico em biocombustível.

Tabela 1 - Caracterização quanto ao sexo e idade média dos alunos pertencentes aos terceiros e quartos anos dos cursos técnicos integrados do IFRN Apodi $(n=138)$

\begin{tabular}{ccccc}
\hline \multirow{2}{*}{ Curso } & \multirow{2}{*}{ Ano } & \multicolumn{2}{c}{ Sexo } & \multirow{2}{*}{ Idade média (anos) } \\
\cline { 3 - 5 } & & $\mathbf{M}$ & $\mathbf{F}$ & \\
\hline \multirow{2}{*}{ Técnico em Zootecnia } & 4 & $37,1 \%$ & $62,9 \%$ & 17,7 \\
& 30 & $26,1 \%$ & $73,9 \%$ & 17,0 \\
\hline \multirow{2}{*}{ Técnico em Biocombustíveis } & 4 & $26,7 \%$ & $73,3 \%$ & 17,6 \\
& 3을 & $65,7 \%$ & $34,3 \%$ & 17,1 \\
\hline Total geral & - & $39,1 \%$ & $60,9 \%$ & 17,4 \\
\hline
\end{tabular}

A taxa de mulheres é bem superior à dos homens, o que pode contribuir para a inserção das mesmas no mercado de trabalho. A maioria feminina também é observada em outros estudos como o apresentado no Anuário Brasileiro da educação básica (2012) que informa que as mulheres são $56,7 \%$ dos alunos.

Segundo o DIEESE (2014), como característica estrutural do mercado de trabalho formal brasileiro, observa-se que as mulheres exercem predomínio nos empregos ocupados por trabalhadores com maior escolaridade. Em 2013, 59,1\% dos empregos ocupados por pessoas com ensino superior completo eram destinados a mulheres. Para aqueles que eram exercidos por quem tinha ensino superior incompleto, a participação das trabalhadoras era de 52,2\%. Na faixa de ensino médio completo, mesmo que elas não fossem maioria $(44,2 \%)$, sua participação ainda era relativamente maior do que o total da participação feminina no mercado de trabalho formal (42,8\%). Em contraposição, a participação das trabalhadoras nas faixas de menor escolaridade atinge o máximo de $28,7 \%$ na faixa da 6 à à 9 a série do ensino fundamental.

$\mathrm{Na}$ Tabela 2, são observados os dados referentes à qualificação desejada dos alunos frente ao estudo em algum curso de graduação e a instituição de ensino superior (IES) de preferência.

Tabela 2 - Expectativa pós-curso dos alunos pertencentes ao terceiro e quartos anos dos cursos técnicos integrados do IFRN Apodi $(n=138)$

\begin{tabular}{|c|c|c|c|c|c|c|c|c|c|}
\hline \multirow[t]{2}{*}{ Curso } & \multirow[t]{2}{*}{ Ano } & \multicolumn{2}{|c|}{$\begin{array}{l}\text { Você tentará } \\
\text { algum curso } \\
\text { superior? }\end{array}$} & \multicolumn{6}{|c|}{ Se sim, onde? } \\
\hline & & Sim & Não & IFRN $^{1}$ & UFERSA $^{2}$ & UFRN $^{3}$ & UERN $^{4}$ & UNP $^{5}$ & Outros $^{6}$ \\
\hline Técnico em & 40 & $100,0 \%$ & $0,0 \%$ & $0,0 \%$ & $48,8 \%$ & $39,0 \%$ & $7,3 \%$ & $2,4 \%$ & $2,4 \%$ \\
\hline Zootecnia & 30 & $95,7 \%$ & $4,3 \%$ & $0,0 \%$ & $27,0 \%$ & $37,8 \%$ & $18,9 \%$ & $13,5 \%$ & $2,7 \%$ \\
\hline Técnico em & 40 & $100,0 \%$ & $0,0 \%$ & $0,0 \%$ & $33,9 \%$ & $38,7 \%$ & $12,9 \%$ & $3,2 \%$ & $11,3 \%$ \\
\hline Biocombustíveis & 3 은 & $100,0 \%$ & $0,0 \%$ & $0,0 \%$ & $38,6 \%$ & $54,5 \%$ & $0,0 \%$ & $6,8 \%$ & $0,0 \%$ \\
\hline Total geral & - & $99,3 \%$ & $0,7 \%$ & $0,0 \%$ & $37,0 \%$ & $42,4 \%$ & $9,8 \%$ & $6,0 \%$ & $4,9 \%$ \\
\hline
\end{tabular}


${ }^{1}$ Instituto Federal de Educação, Ciência e Tecnologia do Rio Grande do Norte; ${ }^{2}$ Universidade Federal Rural do Semiárido; ${ }^{3}$ Universidade Federal do Rio Grande do Norte; ${ }^{4}$ Universidade Estadual do Rio Grande do Norte; ${ }^{5}$ Universidade Potiguar; ${ }^{6}$ Universidade Federal do Ceará; Universidade Federal de Campina Grande; Universidade Federal da Paraíba; Instituto Tecnológico da Aeronáutica; Universidade de São Paulo.

Os resultados em relação às expectativas dos alunos quanto aos cursos superiores mostraram que $99,3 \%$ dos alunos almejam ingressar em alguma faculdade e apenas $0,7 \%$ não pretendem fazer curso superior. Em sua maioria os alunos optam por universidades públicas ao invés das particulares, mostrando a importância que as IES federais e estaduais tem no papel de formação do profissional brasileiro. Além disso, mostra um amadurecimento dos mesmos, pois entendem que a formação técnica pode ser complementada pelo ensino superior. Sparta e Gomes (2005) corroboram a ideia de que o ingresso na educação superior tem sido valorizado como alternativa principal de escolha para os jovens que chegam ao fim do ensino médio.

Dados diferentes foram observados por Penatieri et al. (2012), que trabalharam com jovens do ensino integrado do Instituto Federal Fluminense (IFF), onde, aproximadamente 70\% (setenta por cento) dos alunos entrevistados disseram que pretendem começar a trabalhar assim que acabar a escolarização básica, situação facilitada, segundo os mesmos autores, pela formação profissional recebida. Nessa mesma pesquisa, alguns afirmaram que o ensino médio realizado na modalidade integrada dificulta os planos dos que querem fazer um ensino superior. Outros, de renda familiar inferior, defendem o ensino médio integrado como possibilidade de entrar o mais rápido possível no mercado de trabalho. Pode-se afirmar assim que a entrada no mercado de trabalho é uma forma de alcançar o mais rápido possível a independência e a ajudar na subsistência da família. Esse fato mostra que o lugar do trabalho não está dissociado do perfil dos sujeitos, em que aspectos como escolaridade, profissão dos pais e renda familiar - este último principalmente - interfere sobremaneira na decisão de começar a trabalhar de imediato ou não.

A pesquisa atual mostra uma divergência quanto a perspectiva dos alunos referente à suas atuações após o termino do curso técnico integrado, enquanto Penatieri et al. (2012) identifica a maior parte dos alunos com interesse no mercado de trabalho, os alunos do IFRN Apodi apresentam mais interesse em iniciar um curso de ensino superior. Dentre as explicações possíveis, pode-se relacionar a natureza do curso técnico, Eletrotécnica (UFF) e Zootecnia e Biocombustíveis (IFRN), sendo estes dois últimos implementados recentemente em uma região onde economia local não possui um mercado formalizado com ofertas de empregos atrativos.

Para Sparta e Gomes (2005), as influências marcantes de escolha profissional acabam se reduzindo ao papel histórico do ensino médio como preparatório para a educação superior, à desvalorização da educação profissional como alternativa de estudo para a população carente ou para quem não tem interesse no ensino superior, e a percepção da educação superior como alternativa de profissionalização de maior status social.

Um fator de destaque na atual pesquisa foi a não citação do IFRN como possível estabelecimento para cursar uma graduação. O IFRN, na cidade de Apodi apresenta como única opção de graduação a licenciatura em química, todavia esse curso não foi citado pelos entrevistados como alternativa de graduação, o que explica a ausência de citação do instituto, fato este diretamente relacionado com a falta de estímulo e valorização, que historicamente os professores vivenciam no Brasil, o que leva a uma baixa procura pelos cursos de formação de 
professores. Para Oliveira e Feldfeber (2006) e Scheibe (2010), outros fatores que não estimulam a busca pelas licenciaturas são a deterioração das condições de trabalho, esta decorrente das longas jornadas, de salas superlotadas, do crescimento da indisciplina e da violência na escola, da dificuldade em realizar atualizações de conteúdo e metodológicas, das cobranças de maior desempenho profissional. Estes resultados mostram que é necessário e urgente políticas públicas que fomentem e apoie a valorização do magistério no País, com melhorias nas questões salariais, estruturais, formação continuada e gestão participativa (NEUBAUER et al., 2011), o que contribuiria para a verticalização do ensino, ou seja, o aluno que cursou o ensino médio no IFRN Apodi teria a possibilidade de permanecer na instituição no ensino superior.

$\mathrm{Na}$ tabela 3, são mostrados os 10 cursos de graduação de preferência dos alunos concluintes dos terceiros e quartos anos dos cursos técnicos integrados do IFRN.

Tabela 3 - Pretensão do curso superior dos alunos pertencentes aos terceiros e quartos anos dos cursos técnicos integrados do IFRN Apodi

\begin{tabular}{cccccc}
\hline \multirow{2}{*}{ Curso } & \multirow{2}{*}{ Total } & \multicolumn{2}{c}{ Técnico em Zootecnia } & \multicolumn{2}{c}{ Técnico em Biocombustíveis } \\
\cline { 5 - 7 } & & $\mathbf{3 0}$ & $\mathbf{4 9}$ & $\mathbf{3 0}$ & $\mathbf{4 9}$ \\
\hline Medicina & $13,0 \%$ & $10,0 \%$ & $12,8 \%$ & $11,6 \%$ & $15,6 \%$ \\
Ciência e tecnologia & $11,4 \%$ & - & $4,3 \%$ & $14,0 \%$ & $21,4 \%$ \\
Engenharia Química & $9,2 \%$ & $3,3 \%$ & $2,1 \%$ & $7,0 \%$ & $18,8 \%$ \\
Engenharia Civil & $7,1 \%$ & $6,7 \%$ & $2,1 \%$ & $16,3 \%$ & $4,7 \%$ \\
Direito & $6,5 \%$ & - & $14,9 \%$ & - & $6,3 \%$ \\
Medicina Veterinária & $6,5 \%$ & $16,7 \%$ & $14,9 \%$ & - & - \\
Arquitetura e urbanismo & $4,9 \%$ & $6,7 \%$ & $4,3 \%$ & $11,6 \%$ & - \\
Odontologia & $4,3 \%$ & - & $4,3 \%$ & $4,7 \%$ & $6,3 \%$ \\
Psicologia & $4,3 \%$ & $6,7 \%$ & $4,3 \%$ & $4,7 \%$ & $3,1 \%$ \\
Engenharia Mecânica & $3,3 \%$ & - & - & $9,3 \%$ & $3,1 \%$ \\
Não sabe & $5,4 \%$ & $16,7 \%$ & $4,3 \%$ & $7,0 \%$ & - \\
Outros ${ }^{1}$ & $25,7 \%$ & $33,2 \%$ & $31,7 \%$ & $13,8 \%$ & $20,7 \%$ \\
\hline
\end{tabular}

${ }^{1}$ Engenharia mecânica, Farmácia, Nutrição, Agronomia, Geologia, Zootecnia, Administração, Biologia, Biotecnologia, Ciência da computação, Engenharia de produção, Engenharia elétrica, Fisioterapia, Letras, Biomedicina, Contabilidade, Educação física, Engenharia Aero Espacial, Engenharia de Software, Geografia, História, Jornalismo, Serviço social.

O curso mais citado pelos alunos do IFRN Apodi, de uma maneira geral, foi o de Medicina, dado esse que converge com o jornal Tribuna do Norte (2013), que divulgou a demanda parcial do vestibular de 2013 da UFRN, que teve o curso de Medicina como o mais concorrido. No vestibular da UERN, segundo a Gazeta do oeste (2013), o curso de medicina registrou 1.862 inscritos e uma concorrência de 143,23 candidatos por vaga oferecida. Isso pode ser explicado pela valorização social, alta empregabilidade e remuneração atrativa do curso de medicina (NASCIMENTO et al., 2013).

Com relação aos cursos de graduação relacionados diretamente às áreas dos cursos técnicos, tem-se que para o Técnico em Zootecnia, o curso de Medicina Veterinária foi o mais citado, enquanto que no curso de Técnico em Biocombustíveis, foi a graduação de C\&T (ciência e tecnologia) que oferece oportunidade de migrar para alguma das Engenharias, o mais citado. Isso demonstra que curso técnico do discente influencia a sua opção pela graduação.

Para Tozzi (2004), é fácil constatar uma dúvida que persegue boa parte dos candidatos à universidade: que profissão escolher? Em geral, trata-se de uma escolha quando ainda o estudante não tem domínio das questões básicas em relação à futura profissão. Com 17 ou 18 
anos de idade, em média, esta é certamente a decisão mais difícil que irá tomar na vida. Recém saída da adolescência, a maioria carece de segurança emocional e vivência profissional.

Segundo Malacarne (2007), é importante considerar que a escolha profissional está condicionada as diferentes influências, entre as quais estão as expectativas familiares, as situações sociais, culturais e econômicas, as oportunidades educacionais, as perspectivas profissionais da região onde reside e as próprias motivações do sujeito. Se estes aspectos não são levados em consideração, pode haver frustrações profundas no indivíduo e na sua relação com o mundo do trabalho.

Algumas ações podem ser sugeridas como ferramenta para fornecer base mais sólida para uma escolha mais equilibrada e em consonância com perfil e individualidade de cada sujeito, entre elas, destaca-se:

- Realização de eventos de divulgação das diferentes profissões, com ênfase nas peculiaridades, profissionais de sucesso, atribuições e importância de cada profissional na sociedade.

- Visitas técnicas buscando apresentar a rotina diária de cada profissão ao longo do ensino médio

- Incentivar a participação dos alunos em projetos de pesquisa e extensão em diferentes áreas do conhecimento.

Os resultados frente à possibilidade de desistência dos cursos técnicos integrados para os alunos do quarto ano estão expressos na tabela 4.

Para os alunos de quartos anos foi feito a seguinte pergunta: Caso você passe para um curso superior antes do fim do ano letivo, você desistiria do curso técnico do IFRN? A maioria $(86,1 \%)$ respondeu que não, alegando já se encontrarem próximos da conclusão do curso e que o mesmo possuía importância para o currículo, conhecimento, e também a possibilidade de inserção dos mesmos no mercado de trabalho. Os alunos que responderam que sim $(13,9 \%)$, argumentaram que o curso não se encontrava na área que pretendiam seguir em sua carreira de trabalho (Tabela 4).

Tabela 4 - Respostas dos alunos do quarto ano frente à pergunta: Caso você passe para um curso superior antes do fim do ano letivo, você desistiria do curso técnico do IF?

\begin{tabular}{ccc}
\hline \multirow{2}{*}{ Curso } & \multicolumn{2}{c}{ Caso você passe para um curso superior antes do fim do ano letivo, você desistiria do } \\
& Surso técnico do IF? & Não \\
\cline { 2 - 3 } & $11,4 \%$ & $88,6 \%$ \\
Técnico em Zootecnia & & $84,1 \%$ \\
$\begin{array}{c}\text { Técnico em } \\
\text { Biocombustíveis }\end{array}$ & $15,9 \%$ & $86,1 \%$ \\
\hline Total geral & $13,9 \%$ & 8 \\
\hline
\end{tabular}

A desistência dos cursos técnicos implicaria no não recebimento do certificado do curso técnico, porém se o aluno atender os requisitos necessários do Ministério da Educação (2014) poderá receber o certificado de conclusão do ensino médio e ingressar em algum curso superior.

$\mathrm{Na}$ tabela 5 são apresentados os resultados sobre a prática profissional dos alunos, pois a mesma é obrigatória para todos os discentes do curso técnico e possui uma carga de $400 \mathrm{~h} / \mathrm{a}$ 
que pode ser desenvolvida na forma de estágio ou na execução de projeto de pesquisa ou extensão.

Tabela 5 - Prática profissional dos alunos pertencentes aos terceiros e quartos anos dos cursos técnicos integrados do IFRN Apodi

\begin{tabular}{cccccc}
\hline & & \multicolumn{2}{c}{$\begin{array}{c}\text { Você já fez ou está fazendo a prática } \\
\text { profissional }\end{array}$} & Ano & \multicolumn{2}{c}{ Se sim, é na forma de: } \\
\cline { 3 - 6 } & & Sim & Não & Estágios & $\begin{array}{c}\text { Projetos de pesquisa ou } \\
\text { extensão }\end{array}$ \\
\hline \multirow{2}{*}{ Técnico em Zootecnia } & $4 \underline{0}$ & $74,3 \%$ & $25,7 \%$ & $26,9 \%$ & $73,1 \%$ \\
Técnico em & 30 & $13,0 \%$ & $87,0 \%$ & $33,3 \%$ & $66,7 \%$ \\
biocombustíveis & 40 & $66,7 \%$ & $33,3 \%$ & $0,0 \%$ & $100,0 \%$ \\
\hline Total geral & 3o & $60,0 \%$ & $40,0 \%$ & $0,0 \%$ & $100,0 \%$ \\
\hline
\end{tabular}

Os resultados referentes à prática profissional, que todos os alunos devem realizar, mostraram que a maioria $(58,0 \%)$ dos alunos já fez ou está fazendo a mesma, sendo que $89,9 \%$ das práticas são por meio de projetos de pesquisa e extensão. Os alunos que ainda não iniciaram a pratica profissional justificaram a falta de oportunidade como principal agente, alegam também falta de esclarecimentos sobre o trabalho de conclusão de curso e alguns afirmaram que preferem fazê-la apenas quando o fim do curso estiver próximo. Com relação às diferenças encontradas entre os cursos, percebe-se que os alunos do curso de técnico em Zootecnia (26,9\% - 40 ano; 33,3\% - 3o ano) executam a prática na forma de estágio, pois a realidade do curso permite que o estágio possa ser executado em fazendas ou estabelecimentos rurais, fato que não ocorre com o curso de Técnico em Biocombustíveis (TRIBUNA DO NORTE, 2014) que necessita de estrutura industrial e o município de Apodi e região não fornece as condições, pois não possui indústrias na área. Além do fato do IFRN Apodi ainda não contar com infraestrutura para estágios profissional nos laboratórios consolidada.

Em pesquisa divulgada pelo jornal Tribuna do norte (2014) sobre os alunos egressos do IFRN, foi ressaltado que o estágio é o fator mais importante na entrada dos alunos no mercado de trabalho, logo o fato de apenas 10,1\% dos alunos do IFRN Apodi estagiarem é preocupante na inserção dos mesmos no mercado de trabalho.

Na tabela 6 estão os dados referentes à satisfação dos discentes sobre a qualidade das aulas das disciplinas básicas, técnicas e quantidade de aulas práticas.

Tabela 6 - Satisfação dos alunos pertencentes aos terceiros e quartos anos dos cursos técnicos integrados do IFRN Apodi, frente às disciplinas básicas e técnicas e aulas práticas

\begin{tabular}{|c|c|c|c|c|c|c|c|}
\hline \multirow[t]{2}{*}{ Curso } & \multirow[t]{2}{*}{ Ano } & \multicolumn{2}{|c|}{$\begin{array}{l}\text { Você está satisfeito } \\
\text { com a qualidade do } \\
\text { ensino das } \\
\text { disciplinas básicas? }\end{array}$} & \multicolumn{2}{|c|}{$\begin{array}{c}\text { Você está satisfeito } \\
\text { com a qualidade do } \\
\text { ensino das disciplinas } \\
\text { técnicas? }\end{array}$} & \multicolumn{2}{|c|}{$\begin{array}{c}\text { Você está satisfeito } \\
\text { com a quantidade de } \\
\text { aulas práticas do seu } \\
\text { curso? }\end{array}$} \\
\hline & & Sim & Não & Sim & Não & Sim & Não \\
\hline Técnico em & $4 \stackrel{0}{4}$ & $97,1 \%$ & $2,9 \%$ & $97,1 \%$ & $2,9 \%$ & $22,9 \%$ & $77,1 \%$ \\
\hline Zootecnia & 30 & $100,0 \%$ & $0,0 \%$ & $95,7 \%$ & $4,3 \%$ & $43,5 \%$ & $56,5 \%$ \\
\hline \multirow{2}{*}{$\begin{array}{c}\text { Técnico em } \\
\text { biocombustíveis }\end{array}$} & $4 \stackrel{0}{2}$ & $97,8 \%$ & $2,2 \%$ & $95,6 \%$ & $4,4 \%$ & $22,2 \%$ & $77,8 \%$ \\
\hline & 3은 & $100,0 \%$ & $0,0 \%$ & $100,0 \%$ & $0,0 \%$ & $60,0 \%$ & $40,0 \%$ \\
\hline Total geral & & $98,6 \%$ & $1,4 \%$ & $97,1 \%$ & $2,9 \%$ & $35,5 \%$ & $64,5 \%$ \\
\hline \multicolumn{2}{|c|}{ HOLOS, Ano 30, Vol. 5} & & & & & & 160 \\
\hline
\end{tabular}


A satisfação dos alunos com o ensino das disciplinas técnicas e básicas foi elevada. Em contrapartida os alunos não estão satisfeitos com a quantidade de aulas práticas realizadas em seus cursos. Ressalta-se que as mesmas são essenciais para a formação de um profissional mais qualificado, porém a instituição ainda carece de mais infraestrutura quanto a laboratórios e funcionamento da Fazenda Escola para que os alunos convivam ao máximo no ambiente em que devem trabalhar futuramente.

A execução de aulas práticas exige um ambiente adequado e ações conjuntas da gestão, equipe técnica e docentes para sua integralização. A falha em algo destes segmentos pode resultar na não efetivação das aulas práticas, seja por falta de planejamento (professores/gestão), logística, excesso de burocracia e falta de apoio técnico.

As aulas práticas são essenciais e segundo Oliveira (2000) na caracterização da identidade da prática escolar, importa, sobremaneira, o trabalho coletivo que se desenvolve nas escolas técnicas, cujos pilares seriam: os objetivos e a questão da qualificação e formação profissional, as concepções e práticas relativas às relações da escola com a indústria e o mercado de trabalho; e, ainda, as características dos sujeitos escolares que são conhecidas e respeitadas na instituição, que são consideradas como recursos facilitadores/limitadores do trabalho escolar, que influenciam as relações formais (envolvendo questões de gestão) e informais entre eles, e que os tornam membros/não membros da escola.

Outra possibilidade de interagir teoria e prática são as visitas técnicas, que são ferramentas que devem ser utilizadas pelos professores para o aperfeiçoamento do ensino. Segundo Costa e Araújo (2012), essas visitas são recursos pedagógicos poderosos na formação dos futuros profissionais, e devem ser utilizadas concomitantemente ao ensino teórico vivenciados em sala de aula. Desse modo, faz se necessário que o professor faça a ponte entre o conteúdo trabalhado e aplique-os de maneira conveniente a visita técnica. É a partir da observação do passo-a-passo no ambiente de trabalho durante o encontro com o universo profissional, que se oportuniza aos estudantes uma formação ampla ao observar a organização e a dinâmica de uma empresa em pleno funcionamento. Durante a visita o aluno pode perceber as contradições entre o mundo do trabalho e da academia e a difícil conciliação dos objetivos de ensino aprendizagem com aquele do tempo da produção.

$\mathrm{Na}$ tabela 7, está a percepção dos alunos sobre o mercado de trabalho, onde $58,8 \%$ acredita que o curso oferece bom mercado de trabalho, ao mesmo tempo, $71,1 \%$ supõe que a quantidade de turmas formadas pelo IFRN na modalidade subsequente já é suficiente para atender a região.

Tabela 7 - Percepção sobre o mercado de trabalho dos alunos pertencentes aos terceiros e quartos anos dos cursos técnicos integrados do IFRN Apodi

\begin{tabular}{cccccc}
\hline \multirow{2}{*}{$\begin{array}{c}\text { Curso } \\
\end{array}$} & Ano & \multicolumn{2}{c}{$\begin{array}{c}\text { Você acredita que seu curso } \\
\text { oferece um bom mercado de } \\
\text { trabalho? }\end{array}$} & $\begin{array}{c}\text { Você acredita que a quantidade de turmas } \\
\text { formadas pelo IFRN é suficiente para atender a } \\
\text { região? }\end{array}$ \\
\cline { 2 - 6 } & 40 & Sim & Não & Sim & Não \\
\hline Técnico em & $34,3 \%$ & $25,7 \%$ & $74,3 \%$ & $25,7 \%$ \\
Zootecnia & 30 & $42,9 \%$ & $57,1 \%$ & $66,7 \%$ & $33,3 \%$ \\
\hline Técnico em & 40 & $51,1 \%$ & $48,9 \%$ & $77,3 \%$ & $22,7 \%$ \\
biocombustíveis & 30 & $62,9 \%$ & $37,1 \%$ & $62,9 \%$ & $37,1 \%$ \\
\hline Total geral & & $58,8 \%$ & $41,2 \%$ & $71,1 \%$ & $28,9 \%$ \\
\hline
\end{tabular}


Os alunos atestaram que os cursos oferecem bom mercado de trabalho, todavia ainda são novos na região e encontra-se em estado de aceitação. Já os alunos que responderam que o curso não possuía bom mercado de trabalho se justificaram afirmando que este fato ocorria pelo curso também ser novo no mercado de trabalho. O jornal Tribuna do Norte (2014) ao divulgar dados sobre os egressos do IFRN ressaltou que $59 \%$ dos alunos formados por todos os campus do IFRN estão inseridos de alguma forma no mercado de trabalho, porém no IFRN de Apodi, os formados possuem uma taxa de desemprego de $71,2 \%$ e dos que trabalham $80,0 \%$ atuam em área diferente da formada. Dessa forma, a natureza dos cursos técnicos e infraestrutura das cidades são fatores preponderantes para a inserção dos alunos no mercado de trabalho.

Rodrigues (2012) ao trabalhar com alunos do curso de técnico em eletrônica do IFF encontrou que os estudantes apresentam um sentimento geral de insegurança e incertezas em relação ao futuro. Os jovens afirmam que o fato de fazerem um curso técnico em uma instituição de ensino vista como de qualidade nãos thes garante empregabilidade e ascensão profissional.

Ainda segundo esse autor, há uma necessidade urgente de se repensar o ensino técnico. No que tange especificamente a proposição de cursos técnicos de nível médio integrados, há que se superar a ainda existente, visão compensatória, assistencialista, ou mesmo de caráter exclusivamente técnico instrumental, para uma concepção libertadora, que defende a Educação Profissional como essencial para a formação de trabalhadores; sujeitos coletivos e históricos, e para isso, há que se fundamentar na vinculação entre uma formação técnica e uma sólida base científica, integrando a preparação para o trabalho como uma das dimensões educativas do processo de formação humana.

\section{CONCLUSÕES}

De maneira objetiva pode-se dizer que os alunos pesquisados estão satisfeitos com a qualidade das aulas, tanto das disciplinas técnicas como básicas, mas, vêm à necessidade de um maior número de aulas práticas. Outro fato importante é que a maior parte dos alunos pretende seguir direto para o curso superior, não tendo o interesse imediato em trabalhar na área do seu curso técnico.

Diante destes dados percebe-se que políticas públicas que visem atrair estes alunos para o mercado de trabalho podem ser adotadas para qualificar o setor produtivo local. Dentre as medidas que podem ser propostas, destacam-se: Formação continuada dos produtores/empresários locais, mostrando a importância da incorporação de novas técnicas produtivas, onde o aluno do curso técnico seria protagonista nesta formação. Realização de parcerias com instituições de fomento, reconhecendo os alunos e professores das Instituições na elaboração e realização de projetos, o que conferiria importância e reconhecimento por parte do setor produtivo local.

Por fim ressalta-se que a aplicação destas medidas que visam otimizar a qualificação e o desempenho profissional destes alunos dependerá de uma gestão pública democrática que analise a opinião de toda a comunidade escolar. 


\section{REFERÊNCIAS BIBLIOGRÁFICAS}

1. ANUÁRIO BRASILEIRO DA EDUCAÇÃO BÁSICA. Todos pela educação. São Paulo, Ed. Moderna, 2012. <http://www.todospelaeducacao.org.br/biblioteca/1450/anuario-brasileiro-da-educa cao-basica> Acesso em 03 de Outubro de 2014.

2. BRASIL. Lei no. 11.892, de 29 de dezembro de 2008. Institui a Rede Federal de Educação Profissional, Científica e Tecnológica, cria os Institutos Federais de Educação, Ciência e Tecnologia, e dá outras providências. Diário Oficial da União, Seção 1, p. 1, 30/12/2008.

3. COSTA, M.N.M.G.; ARAÚJO, R.P. A importância da visita técnica como recurso didático metodológico. Um relato na prática do IF Sertão Pernambucano. In: VII CONNEPI - Congresso Norte e Nordeste de pesquisa e inovação, Palmas-TO, 5 p., 2012.

4. DIEESE. O mercado de trabalho formal brasileiro: resultado da RAIS 2013. São Paulo: DIEESE, set. 2014. (Notas Técnicas, 140). Disponível em: www.dieese.org.br/notatecnica/2014 /notaTec140Rais2013.pdf

5. INSTITUTO FEDERAL DE EDUCAÇÃO, CIÊNCIA E TECNOLOGIA DO RIO GRANDE DO NORTE IFRN. Projeto Político-Pedagógico do IFRN: uma construção coletiva - Documento base, versão para consulta pública à comunidade acadêmica do IFRN. 328 p. Natal-RN, 2012. . Disponível em: <http://www2.ifrn.edu.br/ppi/doku.php> Acesso em: 11 de Outubro de 2013.

6. MALACARNE, V. et al. A escolha profissional e Ensino Superior: uma experiência a partir da educação de jovens e adultos. In: Anais da XIX Semana de Educação. Cascavel, 2007. p. 01-10.

7. MINISTÉRIO DA EDUCAÇÃO. Guia de certificação do exame nacional do ensino médio. Brasília: 21p., 2014.

8. NASCIMENTO, F.S.; COUTINHO, T.C.; PINHEIRO, J.A. Exame nacional do ensino médio - ENEM: um olhar dos discentes do $3^{\circ}$ ano do ensino médio e sua preparação para o ingresso no ensino superior. Educação em Revista, v. 14, n. 2, p. 69-92, 2013.

9. NEUBAUER, R.; DAVIS, C.; TARTUCE, G.L.B.P.; NUNES, M.M.R. Ensino médio no Brasil: uma análise de melhores práticas e de políticas públicas. R. bras. Est. pedag., v. 92, n. 230, p. 1133, 2011.

10. OLIVEIRA, D.A.; FELDFEBER, M. Políticas educativas y trabajo docente. Buenos Aires: Centro de Publicaciones Educativas y Material Didáctico, 2006.

11. OLIVEIRA, M.R.N.S. Mudanças no mundo do trabalho: Acertos e desacertos na proposta curricular para o Ensino Médio (Resolução CNE 03/98). Diferenças entre formação técnica e formação tecnológica. Educação \& Sociedade, ano XXI, n. 70, p. 40-62, 2000.

12. PENATIERI, G.R.; FALCÃO, C.R.; MARTíNEZ, S.A. Ao final da educação básica: o que pensam jovens alunos sobre suas escolarizações, suas juventudes e seus projetos. Educ. foco, v. 16, n. 2, p. 117-139, 2012.

13. REDAÇÃO. Medicina registra maior concorrencia do PSV/Uern 2013. Gazeta do Oeste, Disponível em: http://www.gazetadooeste.com.br/mossoro-medicina-registra-a-maior- con correncia-do-psvuern-2013-8689 > Acesso em 01/07/2013.

14. RODRIGUES, C.M. Jovens alunos da educação profissional tecnológica: a experiências da formação integrada e as perspectivas para a inserção no mundo do trabalho. In: XVI ENDIPE Encontro Nacional de Didática e Práticas de Ensino. UNICAMP, 12 p., 201212. 
15. SCHEIBE, L. Valorização e formação dos professores para a educação básica: questões desafiadoras para um novo plano nacional de educação. Educ. Soc., v. 31, n. 112, p. 981-1000, 2010.

16. SPARTA, M.; GOMES, W.B. Importância Atribuída ao Ingresso na Educação Superior por Alunos do Ensino Médio. Revista Brasileira de Orientação Profissional, v.6, n.2, p. 45 - 53, 2005.

17. TOZZI, M. et al. Novos paradigmas na educação em engenharia. Curitiba: ABENGE, 2007.

18. TRIBUNA DO NORTE, REDAÇÃO. UFRN divulga demanda parcial do vestibular 2013. Tribuna doNorte, Disponível em: http://tribunadonorte.com.br/noticia/ufrn-divulga-demandaparcial-do-vestibular-2013/231572> Acesso em 14/07/2013.

19. TRIBUNA DO NORTE, Nadjara Martins. IFRN consegue empregar $60 \%$ dos alunos. Tribuna do Norte, disponível em: http://tribunadonorte.com.br/noticia/ifrn-consegue-empregar-60-dosalunos/294364> Acesso em 01/10/2014. 